\title{
The Pathology of Orthopedic Implant Failure Is Mediated by Innate Immune System Cytokines
}

\author{
Stefan Landgraeber, ${ }^{1,2}$ Marcus Jäger, ${ }^{1}$ Joshua J. Jacobs, ${ }^{2}$ and Nadim James Hallab ${ }^{2}$ \\ ${ }^{1}$ Department of Orthopaedics, University Hospital Essen, University of Duisburg-Essen, Hufelandstraße 55, 45122 Essen, Germany \\ ${ }^{2}$ Department of Orthopedics, Rush University Medical Center, 1735 W Harrison MC107, Chicago, IL 60612, USA \\ Correspondence should be addressed to Nadim James Hallab; nhallab@rush.edu
}

Received 11 September 2013; Revised 25 March 2014; Accepted 8 April 2014; Published 7 May 2014

Academic Editor: Charles J. Malemud

Copyright (c) 2014 Stefan Landgraeber et al. This is an open access article distributed under the Creative Commons Attribution License, which permits unrestricted use, distribution, and reproduction in any medium, provided the original work is properly cited.

\begin{abstract}
All of the over 1 million total joint replacements implanted in the US each year are expected to eventually fail after 15-25 years of use, due to slow progressive subtle inflammation at the bone implant interface. This inflammatory disease state is caused by implant debris acting, primarily, on innate immune cells, that is, macrophages. This slow progressive pathological bone loss or "aseptic loosening" is a potentially life-threatening condition due to the serious complications in older people ( $>75 \mathrm{yrs})$ of total joint replacement revision surgery. In some people implant debris (particles and ions from metals) can influence the adaptive immune system as well, giving rise to the concept of metal sensitivity. However, a consensus of studies agrees that the dominant form of this response is due to innate reactivity by macrophages to implant debris where both danger (DAMP) and pathogen (PAMP) signalling elicit cytokine-based inflammatory responses. This paper discusses implant debris induced release of the cytokines and chemokines due to activation of the innate (and the adaptive) immune system and the subsequent formation of osteolysis. Different mechanisms of implant-debris reactivity related to the innate immune system are detailed, for example, danger signalling (e.g., IL-1 $\beta$, IL-18, IL33, etc.), toll-like receptor activation (e.g., IL-6, TNF- $\alpha$, etc.), apoptosis (e.g., caspases 3-9), bone catabolism (e.g., TRAP5b), and hypoxia responses (Hif1- $\alpha$ ). Cytokine-based clinical and basic science studies are in progress to provide diagnosis and therapeutic intervention strategies.
\end{abstract}

\section{Introduction}

Total hip and knee replacements are examples of successful surgical interventions with overall success rates of $>90 \%$ at ten years after surgery [1]. However, increasing time after surgery correlates with greater incidence of loosened/failing hip and knee arthroplasties, where survival rates at 15-20 years after operation are very low $<50 \%$. Currently, 40,000 hip arthroplasties have to be revised each year in the US because of painful implant loosening and it is expected that the rates of revision will increase by $137 \%$ for total hip and $601 \%$ for total knee revisions over the next 25 years [2]. Painful loosening is a serious long-term complication because of the high clinical/surgical risks of revision surgery and the associated high health-care costs. The number of revisions is accompanied by diminishing bone stock and the need for even larger implants, which increases the risk profile. Improvements in surgical techniques, materials, and implant designs have reduced the problem over the years by reducing particle production but the underlying problem remains. Thus diagnosing and stopping debris induced osteolysis are particular problems that have not been solved and are needed to improve the long term performance of joint replacement implants.

Aseptic loosening (no infection) is the main cause for revision surgery over the mid- and long-term and is responsible for $>70 \%$ of hip revisions and $>44 \%$ of knee revisions [ 3 , 4]. Various biomechanical factors like micromotion may play a role in the induction of aseptic loosening directly but also indirectly through the formation of additional wear particles. The various implant debris induced biological reactions have been well established as the central causal problem [5-7]. 
This local bone loss (or peri-implant osteolysis) is initiated by aseptic inflammatory responses to phagocytosis of small implant wear particles (generally $<10$ microns in diameter) resulting in increased proliferation and differentiation of osteoclast precursors into mature osteoclasts [8-10]. Various cytokines and chemokines are involved in this inflammatory activation of osteoclasts. This paper will discuss implant debris (e.g., wear particle) induced release of cytokines and chemokines due to activation of the innate and the adaptive immune system and the subsequent formation of osteolysis and how this knowledge is currently used for diagnosis and therapy.

\section{Innate Immune System Response to Wear Debris Particles}

2.1. Macrophages. Inflammatory responses to implant debris over time have been attributed to macrophage reactivity and have been the primary focus of investigation over the past 40 years. Recent studies demonstrate a predominance of M1 macrophages in response to implant debris challenge (released metal ions and particles), which produce primarily proinflammatory mediators that affect other local cell around implants (Figure 1) [11]. Thus, given that wear particles are biologically active and influence the innate immune pathway, the amount, appearance, rate of production, time of exposure, and antigenicity of the wear particulates are important $[12,13]$. It has been shown that macrophages release a host of M1 associated cytokines after contact with wear debris. These include IL- $1 \alpha$, IL-1 $\beta$, IL-6, IL-10, IL-11, IL-15, tumor necrosis factor $\alpha$ (TNF- $\alpha)$, transforming growth factor $\alpha$ (TGF- $\alpha$ ), granulocyte-macrophage colony stimulating factor (GM-CSF), macrophage colony stimulating factor (MCSF), platelet-derived growth factor, and epidermal growth factor (Figure 1) [14]. It is likely that more subtle, less studied cytokines and tissue responses are involved in this reactivity as well. The interaction of all these cytokines is very complex and not fully understood yet. While M-CSF and others activate the formation of osteoclasts directly, IL-1, TNF $\alpha$, and IL-6 can affect osteoblasts and other cells which in turn activate osteoclasts and increase cytokine release by macrophages [14]. GM-CSF is responsible for formation of multinucleate giant cells (MNGCs), which act very similar to osteoclasts.

Chemokine expression by macrophages, fibroblasts, and osteoblasts exposed to implant debris is also a central innate immune effector reaction to implant debris [15-19]. The chemokines, particular to implant aseptic loosening pathology, include IL-8, MCP-1 MIP- $1 \alpha$, CCL17/TARC, and CCL22/MDC [20]. IL-8, a CXC chemokine, is upregulated by macrophages and MSCs in periprosthetic tissues by different types of wear particles like titanium, CoCr, and UMHWPE $[21,22]$. This migration of macrophages and osteoclasts to the sites around implants leads to accelerated osteolysis [20].

Increased expression of MCP-1, MIP1 (CCL-2), and MIP $1 \alpha$ (CCL3) was observed in periprosthetic tissues from failed arthroplasties and also in macrophages analyzed cell culture after exposure to different types of wear particles [16].
In contrast to MIP1 $\alpha$, an increased release of MCP-1 was also observed from fibroblasts after exposure to titanium and PMMA particles [17]. Reactions in vivo to UHMWPE and PMMA particle challenge were judged responsible for recruitment of macrophages [23, 24] given systemic migration of macrophages in a mice model decreased when deficient in the CCR2 receptor [23] or after blocking CCR2 receptor [24]. Blocking CCR1 or CCR2 eliminated the migration of MSCs in vitro and blocking CCL17/TARC and CCL22/MDC in osteoclasts and hFOB and their cognate receptor CCR4 in osteoclasts precursors decreased recruitment of osteoclast precursors to the bone-implant interface [25] and are currently potential targets of future interventions $[24,26]$.

\subsection{Bone Responses}

2.2.1. Osteoclasts. The role of osteoclasts is central to osteolysis, as they are the primary bone resorbing cells. RANK(L) signalling is central for the activation of osteoclasts and activates a variety of downstream signalling pathways required for osteoclast development, but crosstalk with other signalling pathways also fine-tunes bone homeostasis both in normal physiology and disease $[27,28]$. The degree to which other cells with the potential to resorb bone (e.g., macrophages) can participate directly in debris induced osteolysis is not known. The role of released cytokines such as TNF- $\alpha$ is also important, but their contribution to osteoclast formation is currently unclear.

Kadoya et al. showed that MNGCs express some markers which are also expressed by osteoclasts, like tartrate-resistant acid phosphatase (TRAP) and vitronectin receptor (VNR) [29]. This applied to MNGCs located on the bone side of the soft-interfacial-tissue (located between implants and bone) but not to those on the implant side. Additionally, in vitro studies have shown that macrophages, exposed to wear debris particles, are capable of a type of low-grade bone resorption [30]. But although if the bone resorbing activity of macrophages is very reasonable, given their abundance and close ontogenic relationship with osteoclasts, it is far from certain that macrophages participate in bone destruction and further studies will be necessary to clarify their role in this context.

Osteoclasts in turn are also capable of phagocytosing a wide size range of ceramic, polymeric, and metallic wear particles. After particle phagocytosis, they remain fully functional, hormone responsive, bone resorbing cells [31, 32], thus showing that at least in vitro there is substantial plasticity between these key cell types involved in implant associated osteolysis that derive from the same precursor cells in bone marrow. Even participation of the early forms of macrophages and osteoclasts, mesenchymal stem cells, have been implicated in aseptic loosening [21], where the endocytosis of wear particles reduced proliferation and osteogenic differentiation and induces an increased production of IL-8 [21]. The association between MNGC and osteoclast formation does not reflect some sort of transdifferentiation or plasticity, but rather than that all macrophage populations include immature macrophages that form both osteoclasts and mature 


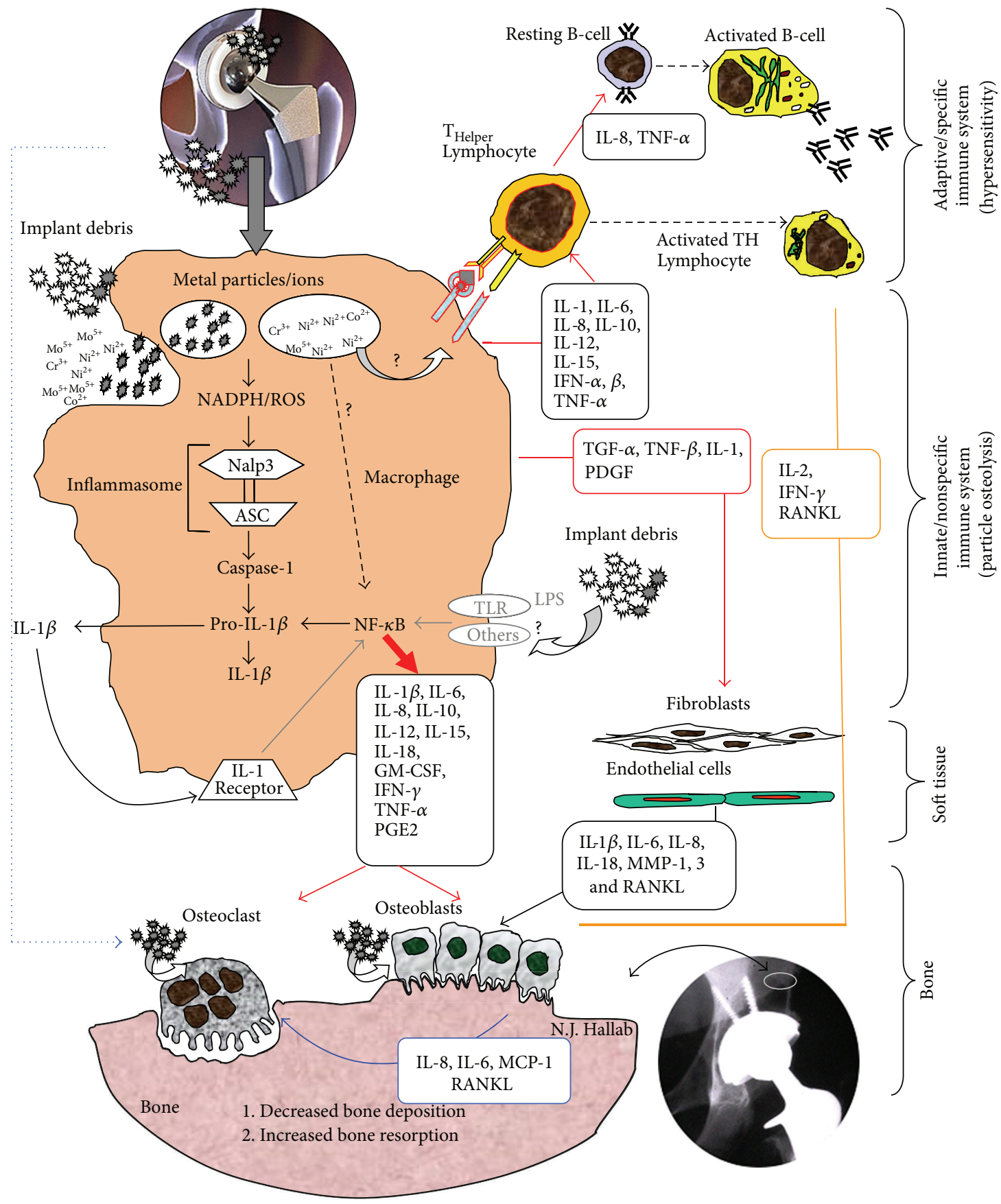

FIGURE 1: Schematic of how the inflammasome pathway is centrally involved in the pathology of implant debris-induced local cytokine responses (courtesy of Bioengineering Solutions Inc.).

macrophages. This makes it difficult to distinguish MNGC from osteoclasts in histological sections unless they are opposed to the bone surface.

2.2.2. Osteoblasts. Osteoblasts are stimulated by wear particles to produce the osteoclastogenesis factors RANKL and M-CSF [33] and cytokines such as IL-6 and IL-8 [34]. The same study also reports a slightly increased expression of VEGF induced by all particle entities and decreased de novo synthesis of type 1 collagen as well as increased expression of matrix metalloproteinase (MMP)-1.

\subsection{Soft Tissue Responses}

2.3.1. Fibroblasts. Soft tissue cells such as fibroblasts are also actively involved in osteoclastogenesis and bone resorption [35]. The most prominent upregulated genes and proteins secreted by fibroblasts in response to wear debris were matrix metalloproteinase 1 (MMP-1), monocyte chemotactic 


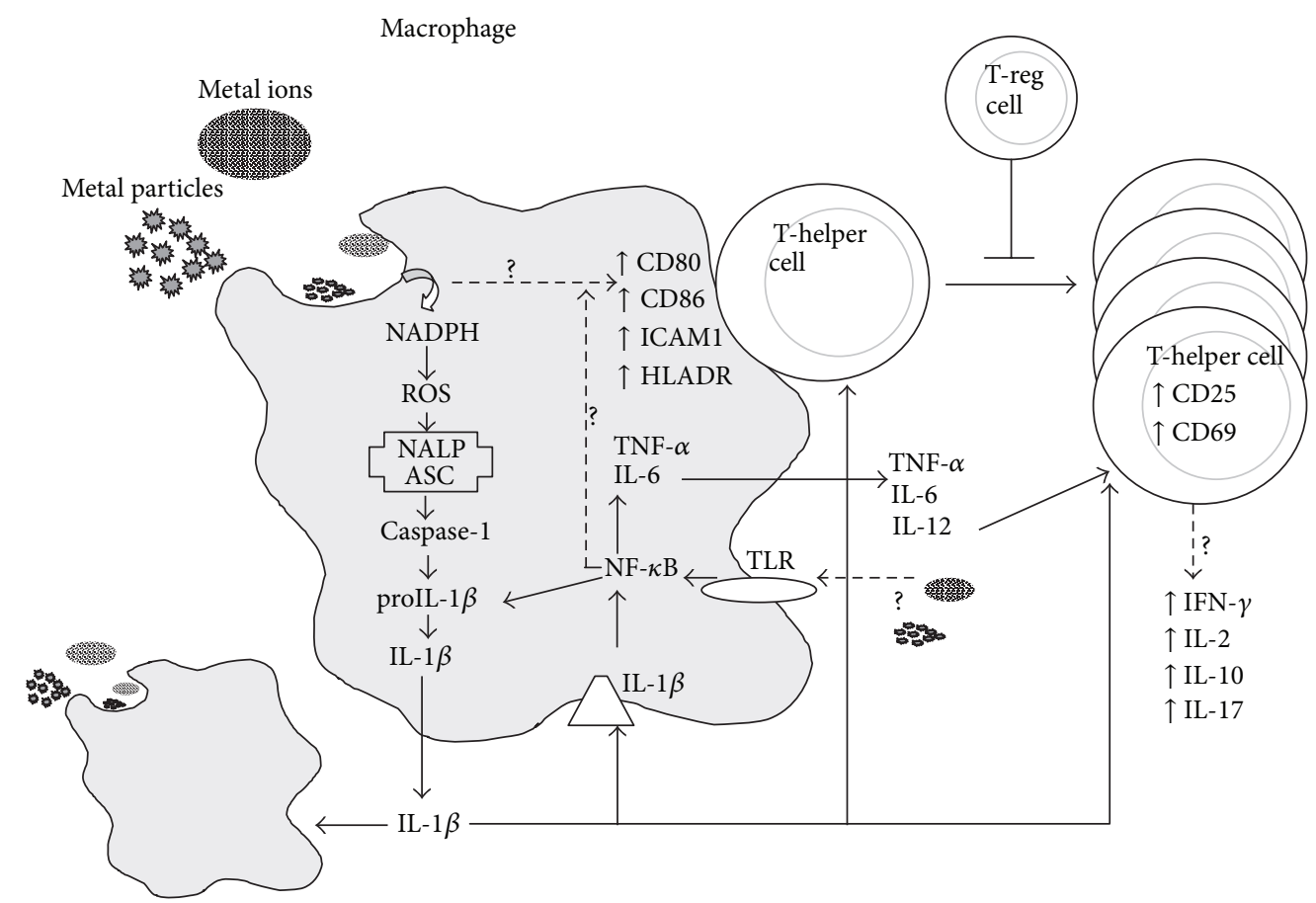

FIGURE 2: Innate immune system (i.e., macrophage) interactions with implant debris produce danger signalling (inflammasome) and pathogen (NF- $\kappa \mathrm{B})$ associated cytokines such as IL- $1 \beta$ and TNF $\alpha$ and increased expression of costimulatory molecules such as CD80/86, ICAM1, and HLADR. These innate responses can trigger adaptive immune responses where destructive TH1 type cytokine profiles require T-regulatory cells (e.g., IL-10) to control this response (courtesy of Bioengineering Solutions Inc.).

protein-1 (MCP-1), IL-1 $\beta$, IL-6, IL-8, cyclooxygenase 1 (cox1 ), cox-2, leukemia inhibitory factor, transforming growth factor beta 1 (TGF $\beta 1$ ), and TGF $\beta$ receptor type I. Stimulated fibroblasts express RANKL and osteoprotegerin.

\subsection{Adaptive Immune Responses}

2.4.1. Lymphocytes. Lymphocytes can play a crucial role in the peri-implant "debris-reactivity" environment as well. It is well recognized that $\mathrm{T}$ and $\mathrm{B}$ lymphocytes are present in periimplant tissues $[36,37]$. The subtypes of $\mathrm{T}$ cells that dominate implant debris associated responses are T-helper (TH) and not T cytotoxic/suppressor (TC/S) which have been found at an in vivo ratio of $7.2: 1$ [38]. Of the T-helper cells present, TH1 cells predominate as characterized by production of IFN- $\gamma$ and IL-2 and to a lesser degree IL-17, fractalkine, and CD40, which indicate the possibility of TH17 activity (versus nonobserved TH2 cell mediated IL-10 responses) $[39,40]$. The involvement of specific lymphocyte responses TH1 cells that can also recruit and activate macrophages, with relatively very few participating local cells, suggests that the role of adaptive immune response may be overlooked and falsely (in some cases) attributed to innate macrophage innate nonspecific immune responses, Figure 2. It has been difficult to readily identify these responses in peri-implant tissues, by such signature cytokines as IL-2, interferon- $\gamma$, TNF- $\alpha$, and IL-2 receptors [41]. But some studies using mRNA detection instead of tissue immunohistochemistry (IL-2) have shown the increased expression of these TH1 cytokines [42, 43].
Furthermore, macrophages and lymphocytes seem to interact with each other via lesser reported coreceptors and cytokines such as IL-15 and its related IL15 receptor (IL-15R $\alpha$ ) on the macrophages, respectively, IL2 receptor (IL-2R $\beta$ ) on the lymphocytes [44]. These TH responses have been characterized as type IV delayed type hypersensitivity. DTH response to metal implant debris is an adaptive slow cell mediated type of response. Metal-antigen sensitized and activated DTH T-cells release various cytokines which recruit and activate macrophages, Figure 2 [38], such as IL-3 and GMCSF (promotes hematopoiesis of granulocytes); monocyte chemotactic activating factor (MCAF) (promotes chemotaxis of monocytes toward areas of DTH activation); IFN- $\gamma$ and TNF- $\beta$ (produce a number of effects on local endothelial cells facilitating infiltration); and migration inhibitory factor (MIF) (signals macrophages to remain in the local area of the DTH reaction). Activated macrophages have increased ability to present class II MHC and IL-2 and can trigger the activation of more T-DTH cells, which in turn recruit/activate more macrophages, which recruit/activate more T-DTH cells, in a runaway cycle of inflammation, without T-regulatory cells (and other factors) to inhibit the response over time. A DTH self-perpetuating response can create extensive tissue damage. Forms of metal sensitivity testing such as lymphocyte transformation test (LTT) and patch testing (for skin reactions) are the only means to predict/diagnose those individuals that will have an excessive immune response to metal exposure that may lead to premature implant failure (approximately $>1-2 \%$ patients/yr) [38]. 


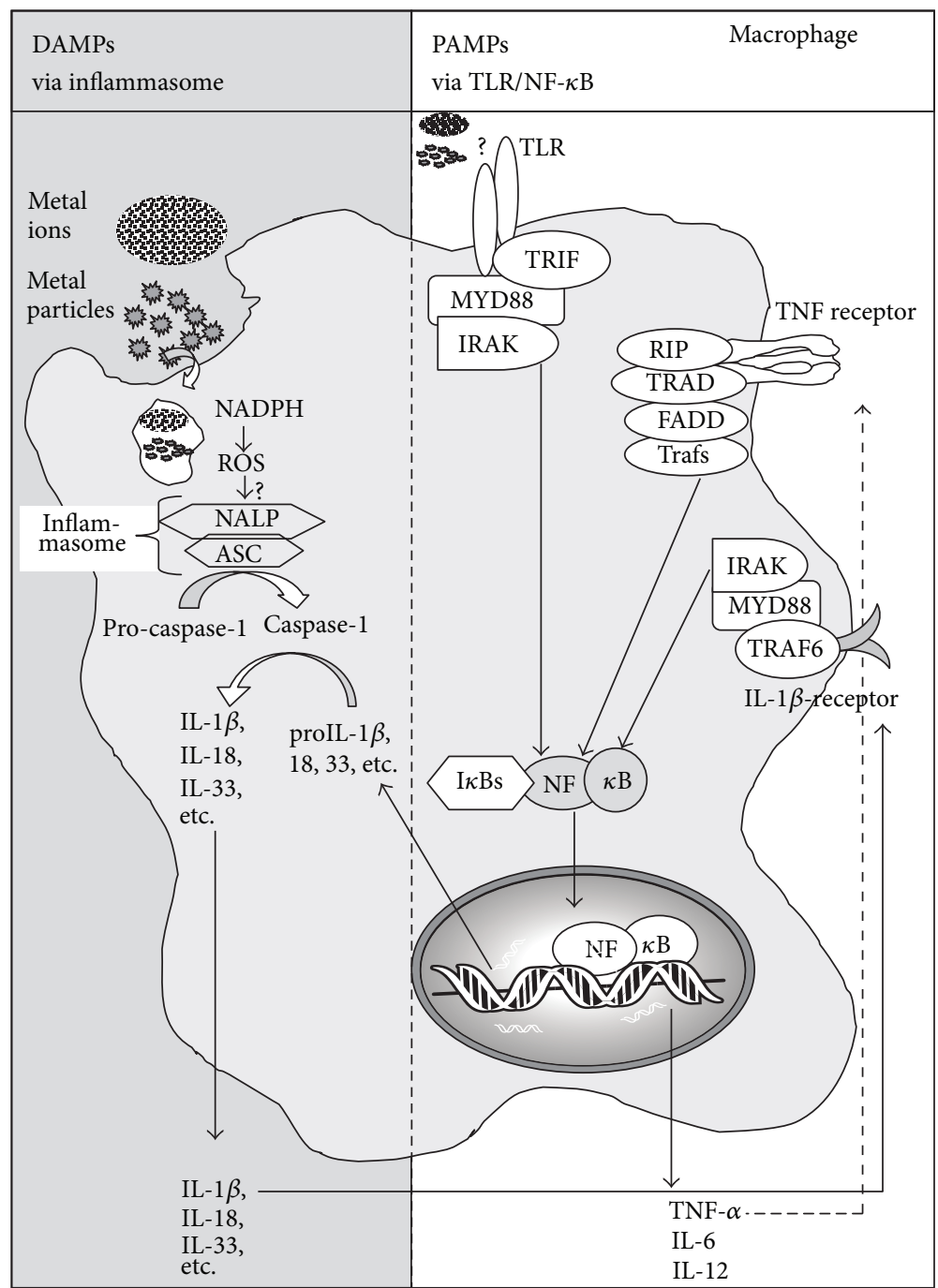

FIGURE 3: Schematic of intracellular innate immune responses to implant debris (metal ions and particles) that produce both DAMP and PAMP pathway activations through lysosomal destabilization (DAMPs) and either TLR or cytokine receptor activation (PAMPs), resulting in the collaborative interaction of the inflammasome and NF- $\kappa$ B pathways (courtesy of Bioengineering Solutions Inc.).

\section{Initial Mechanisms for the Wear Particle Related Activation of the Innate Immune System}

Despite new understandings of implant related cytokine/ chemokines networks that are their release by different periimplant cell types, the mechanisms mediating cellular interaction with debris particles and the subsequent activation of macrophages to produce and release the inflammatory mediators remain incomplete. Past investigations have shown the importance of PAMPs (e.g., toll-like receptors, TLRs) in vivo, in the periprosthetic tissues of patients with aseptic loosening [45-47] and in TLR-knockout mouse models (MyD88 knockout mice) where lower amounts of cytokines and osteolysis were induced by polymethylmethacrylate (PMMA) implant debris particles than wild-type mice $[20,48]$. The MyD88 dependent pathways of TLR signalling result in activation of nuclear factor NF- $\kappa \mathrm{B}$, which has been long shown to play a role in particle induced osteolysis and the production of proinflammatory cytokines such as TNF $\alpha$, IL-1 $\beta$, and IL-12, Figure 3 [49].

Toxicity responses are another facet of innate immune activation where apoptosis and hypoxia responses have been found to be induced by implant debris [50-52]. Soluble and particulate metal debris have been shown to induce hypoxialike pathology resulting in HIF-1 $\alpha$ compensatory responses to metal implant debris by promoting both the induction of hypoxia (HIF-1 $\alpha$ ) and tissue angiogenesis (VEGF) providing a specific mechanism which explains why local soft tissue growths (fibrous pseudotumors) and apoptosis responses can form in some people with certain orthopedic implants [52]. The induction of apoptosis associated processes by implant debris has also been correlated with implant debris in vivo $[53,54]$. And more recently ceramic and polyethylene 
implant debris particles have been shown to induce some form of apoptosis of macrophages in vitro [50, 51]. This in vitro evidence has been supported by in vivo immunohistochemistry of central apoptosis-related mediators such as caspase-3 associated with macrophages, giant cells, and T-lymphocytes in local tissues (capsules and interfacial membranes) of patients with aseptic hip implants $[55,56]$. The importance of apoptosis associated mediators has been made clear by murine osteolysis models that demonstrated inhibition of apoptosis by a pan-caspase inhibitor leads to decreasing bone resorption by osteoclasts [57] and presumably decreased amounts of apoptosis associated cytokines like interleukin-8 (IL-8), monocyte chemoattractant protein1 (MCP-1), intercellular adhesion molecule-1, and type-1 interferon $[58,59]$.

The influence of danger signalling, that is, inflammasome activation, is a relatively new approach in orthopedics. Nonpathogen derived stimuli typically activate immune cells through a danger signal pathways, the central components of which are termed the "inflammasome" [60]. Effective immune system activation requires specific receptors that recognize both pathogen associated molecular patterns (PAMPs) and danger associated molecular patterns (DAMPs) to initiate innate proinflammatory responses, Figures 1 and 3 [61, 62]. Nonpathogen derived danger signals are triggered by DAMPs such as UV light, particulate adjuvants present in modern vaccines $[63,64]$, and recently have been discovered to be activated by implant debris [65]. Typical particulate DAMPs induce lysosomal destabilization, which cause an increase in NADPH (nicotinamide adenine dinucleotide phosphate-oxidase) and an increase in reactive oxygen species (ROS). The release of these intracellular contents is sensed by specific members of the NLR family, such as NALP3 (NACHT-, LRR-, and pyrin domaincontaining protein 3). NALP3 protein, in association with ASC (apoptosis-associated speck-like protein containing a CARD domain), forms the intracellular multiprotein complex, that is, the inflammasome complex [66, 67]. Activation of the inflammasome (NALPs-ASC complex) leads to the cleavage of pro-caspase-1 into active caspase-1 (previously known as ICE, interleukin-1 converting enzyme). Active Caspase-1 is required for the processing and subsequent release of active proinflammatory cytokines such as IL-1 $\beta$ and IL-18 (and others) by cleaving intracellular pro-IL-1 $\beta$, pro-IL18 , and so forth into their mature forms, IL-1b and IL-18. As IL-1 $\beta$ is one of the main cytokines for activation of osteolysis, an involvement in aseptic loosening is obvious, as a recent study has shown less osteolysis in caspase-1 knockout mice [68].

It is well accepted that the inflammatory factors previously described here drive osteoclast formation through progenitor recruitment and RANKL induction; however, the detailed mechanics of how this occurs remains unknown. IL1 , for example, strongly stimulates osteolysis in many contexts but does not affect OC formation directly yet is a very weak inducer of RANKL in bone cells in vitro.

\section{Therapy of Aseptic Loosening by Regulation of the Innate Immune Response}

New biologic treatments addressing the pathology of aseptic implant loosening are currently under development and in clinical trials. Some cytokine inhibitors have been investigated using in vitro and in vivo animal models. Potential treatments include the following. AM630 is a selective inhibitor of cannabinoid recep-
tor 2 that inhibits IL-1 $\beta$ and TNF- $\alpha$ [69].

LY294002 is a specific inhibitor of PI3 K that suppresses the expression of TNF- $\alpha$ [70].

Tetrazykline inhibits MMP-9 [71].

Simvastatin decreases ERK1/2 a phosphorylated protein which is stimulated by wear particles and involved in cell signalling activation of macrophages [72].

None of the aforementioned cytokine regulating drugs have been tested in clinical trials, due to the serious side effects and risks associated with immunosuppressive medications. Other potential candidates (for clinical treatment) include drugs indicated for the treatment of rheumatoid arthritis and other inflammatory diseases, such as traditional nonsteroidal anti-inflammatory drugs (NSAIDs), selective cyclooxygenase (COX) inhibitors (e.g., celecoxib), tumor necrosis factor (TNF) antagonists (e.g., etanercept, infliximab, adalimumab), and interleukin-1 antagonists (e.g., anakinra) [73]. However many investigators remain concerned about the application of these drugs for this pathology due to the antianabolic effects of NSAIDs and COX-2 inhibitors, and the immunosuppressive effects of the antiinflammatory drugs [73]. Newer drugs using small interfering RNA (siRNA) have shown promise in vivo where a mouse model demonstrated that local delivery of lentivirusmediated TNF- $\alpha$ small interfering RNA (siRNA) resulted in less implant debris induced TNF- $\alpha$, IL-1, and IL- 6 and overall in a less associated inflammation [74].

Furthermore, without clinically validated early detection biomarkers of implant loosening, by the time patients presents with pain and radiological evidence of loosening the implant is mechanically loose, and the associated continuous micromotion acts to prevent reintegration even if implant debris associated inflammation-induced osteolysis is arrested [73]. Thus diagnosis of early stages of aseptic loosening is paramount and is the focus of much continued research. Other nonimmune related counter measures to implant debris induced osteolysis have also focused on enhancing bone responses in the face of inflammation. Although beyond the scope of this review, two noteworthy antibone-resorption (i.e., osteoclast inhibiting) bisphosphonates (Etidronate and Alendronate) are currently being evaluated for long-term therapy [75-78], although the embrittlement of bone and cases of early fracture have tempered these efforts. 


\section{Conclusion}

The serious pathology of aseptic osteolysis around joint replacement implants is intimately dependent on cytokines and chemokines released by innate and adaptive immune reactions and local cells around implants. These types of debris-induced inflammation are dominated by innate immune cell (macrophages) secretion of TNF $\alpha$, IL-1 $\beta$, IL6 , and PGE2, which causes peri-implant bone resorption. Given the increasing number of people receiving orthopedic implants the issue of biologic reactivity is growing more prevalent. There is a growing need for more targeted approaches of diagnosis and early intervention of unwanted debris-induced inflammation. New understanding of how sterile nonpathogen implant debris causes immune activation and other local reaction continue to be discovered, such as the inflammasome "danger signalling" pathway [60], and the induction of hypoxia and apoptosis related reactivity [52, $55,56,79]$. Consequently new therapies (such as anti-TNFinfliximab, anti-IL-1 $\beta$, IL-1 $\beta$-receptor-antagonist anakinra, etc.) are under current investigation as targeting measurement and pharmacologic interventions. New diagnostic testing modalities (e.g., cytokines, chemokines, bone metabolism markers, and lymphocyte testing, LTT) are under investigation as candidate early diagnostic measures of debris induced inflammation. Soon these studies will lead to early detection and thus treatment of debris induced inflammation leading to improved long term implant performance.

\section{Conflict of Interests}

The authors declare that they have no conflict of interest regarding the publication of this paper.

\section{References}

[1] T. M. Wright and S. B. Goodman, Implant Wear in Total Joint Replacement: Clinical and Biologic Issues, Material and Design Considerations, American Academy of Orthopaedic Surgeons, Rosemont, Ill, USA, 2001.

[2] S. Kurtz, K. Ong, E. Lau, F. Mowat, and M. Halpern, "Projections of primary and revision hip and knee arthroplasty in the United States from 2005 to 2030," Journal of Bone and Joint SurgerySeries A, vol. 89, no. 4, pp. 780-785, 2007.

[3] P. Herberts and H. Malchau, "Long-term registration has improved the quality of hip replacement: a review of the Swedish THR Register comparing 160,000 cases," Acta Orthopaedica Scandinavica, vol. 71, no. 2, pp. 111-121, 2000.

[4] O. Robertsson, K. Knutson, S. Lewold, and L. Lidgren, "The Swedish Knee Arthroplasty Register 1975-1997: an update with special emphasis on 41,223 knees operated on in 1988-1997," Acta Orthopaedica Scandinavica, vol. 72, no. 5, pp. 503-513, 2001.

[5] M. Boehler, H. Plenk Jr., and M. Salzer, "Alumina ceramic bearings for hip endoprostheses: the Austrian experiences," Clinical Orthopaedics and Related Research, no. 379, pp. 85-93, 2000.

[6] S. Santavirta, M. Takagi, E. Gómez-Barrena et al., "Studies of host response to orthopedic implants and biomaterials," Journal of Long-Term Effects of Medical Implants, vol. 9, no. 1-2, pp. 6776, 1999.

[7] H.-G. Willert, H. Bertram, and G. Hans Buchhorn, “Osteolysis in alloarthroplasty of the hip: the role of ultra-high molecular weight polyethylene wear particles," Clinical Orthopaedics and Related Research, no. 258, pp. 95-107, 1990.

[8] E. M. Schwarz, A. P. Lu, J. J. Goater et al., "Tumor necrosis factor- $\alpha /$ nuclear transcription factor- $\kappa \mathrm{B}$ signaling in periprosthetic osteolysis," Journal of Orthopaedic Research, vol. 18, no. 3, pp. 472-480, 2000.

[9] M. J. Silva and L. J. Sandell, "What's new in orthopaedic research," Journal of Bone and Joint Surgery-Series A, vol. 84, no. 8, pp. 1490-1496, 2002.

[10] J. T. Wang, "The role of particulate orthopaedic implant materials in peri-implant osteolysis," in Biological, Material, and Mechanical Considerations of Joint Replacement, B. F. Morrey, Ed., pp. 1-122, Raven Press, New York, NY, USA, 1993.

[11] A. J. Rao, E. Gibon, T. Ma, Z. Yao, R. L. Smith, and S. B. Goodman, "Revision joint replacement, wear particles, and macrophage polarization," Acta Biomaterialia, vol. 8, no. 7, pp. 2815-2823, 2012.

[12] Y. Kadoya, P. A. Revell, A. Kobayashi, N. Al-Saffar, G. Scott, and M. A. R. Freeman, "Wear particulate species and bone loss in failed total joint arthroplasties," Clinical Orthopaedics and Related Research, no. 340, pp. 118-129, 1997.

[13] A. S. Shanbhag, J. J. Jacobs, J. Black, J. O. Galante, and T. T. Glant, "Macrophage/particle interactions: effect of size, composition and surface area," Journal of Biomedical Materials Research, vol. 28, no. 1, pp. 81-90, 1994.

[14] P. A. Revell, "Biological causes of prosthesis joint failure," in Joint Replacement Technology, P. A. Revell, Ed., pp. 349-396, Woodhead Publishing Limited and CRC Press LLC, Cambridge, UK, 2008.

[15] M. Lind, M. C. D. Trindade, D. J. Schurman, S. B. Goodman, and R. L. Smith, "Monocyte migration inhibitory factor synthesis and gene expression in particle-activated macrophages," Cytokine, vol. 12, no. 7, pp. 909-913, 2000.

[16] Y. Nakashima, D.-H. Sun, M. C. D. Trindade et al., "Induction of macrophage $\mathrm{C}-\mathrm{C}$ chemokine expression by titanium alloy and bone cement particles," Journal of Bone and Joint Surgery - Series $B$, vol. 81, no. 1, pp. 155-162, 1999.

[17] B. Yaszay, M. C. D. Trindade, M. Lind, S. B. Goodman, and R. L. Smith, "Fibroblast expression of C-C chemokines in response to orthopaedic biomaterial particle challenge in vitro," Journal of Orthopaedic Research, vol. 19, no. 5, pp. 970-976, 2001.

[18] P.-G. Ren, Z. Huang, T. Ma, S. Biswal, R. L. Smith, and S. B. Goodman, "Surveillance of systemic trafficking of macrophages induced by UHMWPE particles in nude mice by noninvasive imaging," Journal of Biomedical Materials Research - Part A, vol. 94, no. 3, pp. 706-711, 2010.

[19] P.-G. Ren, A. Irani, Z. Huang, T. Ma, S. Biswal, and S. B. Goodman, "Continuous infusion of UHMWPE particles induces increased bone macrophages and osteolysis," Clinical Orthopaedics and Related Research, vol. 469, no. 1, pp. 113-122, 2011.

[20] Q. Gu, Q. Shi, and H. Yang, "The role of TLR and chemokine in wear particle-induced aseptic loosening," Journal of Biomedicine and Biotechnology, vol. 2012, Article ID 596870, 9 pages, 2012.

[21] H. Haleem-Smith, E. Argintar, C. Bush et al., "Biological responses of human mesenchymal stem cells to titanium wear 
debris particles," Journal of Orthopaedic Research, vol. 30, no. 6, pp. 853-863, 2012.

[22] A. M. Kaufman, C. I. Alabre, H. E. Rubash, and A. S. Shanbhag, "Human macrophage response to UHMWPE, TiAlV, CoCr, and alumina particles: analysis of multiple cytokines using protein arrays," Journal of Biomedical Materials Research-Part A, vol. 84, no. 2, pp. 464-474, 2008.

[23] E. Gibon, T. Ma, P.-G. Ren et al., "Selective inhibition of the MCP-1-CCR2 ligand-receptor axis decreases systemic trafficking of macrophages in the presence of UHMWPE particles," Journal of Orthopaedic Research, vol. 30, no. 4, pp. 547-553, 2012.

[24] Z. Huang, T. Ma, P.-G. Ren, R. L. Smith, and S. B. Goodman, "Effects of orthopedic polymer particles on chemotaxis of macrophages and mesenchymal stem cells," Journal of Biomedical Materials Research-Part A, vol. 94, no. 4, pp. 1264-1269, 2010.

[25] D. Cadosch, O. P. Gautschi, E. Chan, H.-P. Simmen, and L. Filgueira, "Titanium induced production of chemokines CCL17/TARC and CCL22/MDC in human osteoclasts and osteoblasts," Journal of Biomedical Materials Research-Part A, vol. 92, no. 2, pp. 475-483, 2010.

[26] E. Gibon, Z. Yao, A. J. Rao et al., "Effect of a CCR1 receptor antagonist on systemic trafficking of MSCs and polyethylene particle-associated bone loss," Biomaterials, vol. 33, no. 14, pp. 3632-3638, 2012.

[27] A. Leibbrandt and J. M. Penninger, "RANK(L) as a key target for controlling bone loss," Advances in Experimental Medicine and Biology, vol. 647, pp. 130-145, 2009.

[28] A. Leibbrandt and J. M. Penninger, "RANKL/RANK as key factors for osteoclast development and bone loss in arthropathies," Advances in Experimental Medicine and Biology, vol. 649, pp. 100-113, 2009.

[29] Y. Kadoya, N. Al-Saffar, A. Kobayashi, and P. A. Revell, "The expression of osteoclast markers on foreign body giant cells," Bone and Mineral, vol. 27, no. 2, pp. 85-96, 1994.

[30] N. A. Athanasou, J. Quinn, and C. J. K. Bulstrode, "Resorption of bone by inflammatory cells derived from the joint capsule of hip arthroplasties," Journal of Bone and Joint Surgery-Series B, vol. 74, no. 1, pp. 57-62, 1992.

[31] W. Wang, D. J. Ferguson, J. M. Quinn, A. H. Simpson, and N. A. Athanasou, "Osteoclasts are capable of particle phagocytosis and bone resorption," The Journal of Pathology, vol. 182, no. 1, pp. 92-98, 1997.

[32] W. Wang, D. J. P. Ferguson, J. M. W. Quinn, A. H. R. W. Simpson, and N. A. Athanasou, "Biomaterial particle phagocytosis by bone-resorbing osteoclasts," Journal of Bone and Joint SurgerySeries B, vol. 79, no. 5, pp. 849-856, 1997.

[33] D. P. Pioletti and A. Kottelat, "The influence of wear particles in the expression of osteoclastogenesis factors by osteoblasts," Biomaterials, vol. 25, no. 27, pp. 5803-5808, 2004.

[34] K. Lochner, A. Fritsche, A. Jonitz et al., "The potential role of human osteoblasts for periprosthetic osteolysis following exposure to wear particles," International Journal of Molecular Medicine, vol. 28, no. 6, pp. 1055-1063, 2011.

[35] T. Koreny, M. Tunyogi-Csapó, I. Gál, C. Vermes, J. J. Jacobs, and T. T. Glant, "The role of fibroblasts and fibroblast-derived factors in periprosthetic osteolysis," Arthritis and Rheumatism, vol. 54, no. 10, pp. 3221-3232, 2006.

[36] N. Al-Saffar and P. A. Revell, "Pathology of the bone-implant interfaces," Journal of Long-Term Effects of Medical Implants, vol. 9, no. 4, pp. 319-347, 1999.
[37] P. A. Revell, N. Al-Saffar, and A. Kobayashi, "Biological reaction to debris in relation to joint prostheses," Proceedings of the Institution of Mechanical Engineers, Part H: Journal of Engineering in Medicine, vol. 211, no. 2, pp. 187-197, 1997.

[38] P. A. Revell, "The combined role of wear particles, macrophages and lymphocytes in the loosening of total joint prostheses," Journal of the Royal Society Interface, vol. 5, no. 28, pp. 12631278, 2008.

[39] B. Hercus, S. Saeed, and P. A. Revell, "Expression profile of T cell associated molecules in the interfacial tissue of aseptically loosened prosthetic joints," Journal of Materials Science: Materials in Medicine, vol. 13, no. 12, pp. 1153-1156, 2002.

[40] N. J. Hallab, M. Caicedo, A. Finnegan, and J. J. Jacobs, “Th1 type lymphocyte reactivity to metals in patients with total hip arthroplasty," Journal of Orthopaedic Surgery and Research, vol. 3, no. 1, article 6, 2008.

[41] T.-F. Li, S. Santavirta, V. Waris et al., "No lymphokines in T-cells around loosened hip prostheses," Acta Orthopaedica Scandinavica, vol. 72, no. 3, pp. 241-247, 2001.

[42] B. Hercus and P. A. Revell, "Phenotypic characteristics of T lymphocytes in the interfacial tissue of aseptically loosened prosthetic joints," Journal of Materials Science: Materials in Medicine, vol. 12, no. 10-12, pp. 1063-1067, 2001.

[43] P. A. Revell and S. E. Jellie, "Interleukin 15 production by macrophages in the implant interface membrane of aseptically loosened joint replacements," Journal of Materials Science: Materials in Medicine, vol. 9, no. 12, pp. 727-730, 1998.

[44] S. Saeed and P. A. Revell, "Production and distribution of interleukin 15 and its receptors (IL-15R $\alpha$ and IL-R2 $\beta$ ) in the implant interface tissues obtained during revision of failed total joint replacement," International Journal of Experimental Pathology, vol. 82, no. 3, pp. 201-209, 2001.

[45] T. Lähdeoja, J. Pajarinen, V.-P. Kouri, T. Sillat, J. Salo, and Y. T. Konttinen, "TOll-like receptors and aseptic loosening of hip endoprosthesis-a potential to respond against danger signals?” Journal of Orthopaedic Research, vol. 28, no. 2, pp. 184-190, 2010.

[46] J. Pajarinen, E. Cenni, L. Savarino et al., "Profile of toll-like receptor-positive cells in septic and aseptic loosening of total hip arthroplasty implants," Journal of Biomedical Materials Research-Part A, vol. 94, no. 1, pp. 84-92, 2010.

[47] M. Takagi, Y. Tamaki, H. Hasegawa et al., "Toll-like receptors in the interface membrane around loosening total hip replacement implants," Journal of Biomedical Materials Research-Part A, vol. 81, no. 4, pp. 1017-1026, 2007.

[48] J. I. Pearl, T. Ma, A. R. Irani et al., "Role of the Toll-like receptor pathway in the recognition of orthopedic implant wear-debris particles," Biomaterials, vol. 32, no. 24, pp. 5535-5542, 2011.

[49] R. Maitra, C. C. Clement, B. Scharf et al., "Endosomal damage and TLR2 mediated inflammasome activation by alkane particles in the generation of aseptic osteolysis," Molecular Immunology, vol. 47, no. 2-3, pp. 175-184, 2009.

[50] I. Catelas, A. Petit, D. J. Zukor, R. Marchand, L. Yahia, and O. L. Huk, "Induction of macrophage apoptosis by ceramic and polyethylene particles in vitro," Biomaterials, vol. 20, no. 7, pp. 625-630, 1999.

[51] D. Granchi, E. Cenni, G. Ciapetti et al., "CEll death induced by metal ions: necrosis or apoptosis?” Journal of Materials Science: Materials in Medicine, vol. 9, no. 1, pp. 31-37, 1998.

[52] L. Samelko, M. S. Caicedo, S. J. Lim, C. Della-Valle, J. Jacobs, and N. J. Hallab, "Cobalt-alloy implant debris induce HIF-lalpha hypoxia associated responses: a mechanism for metal-specific 
orthopedic implant failure," PLoS One, vol. 8, no. 6, article e67127, 2013.

[53] O. L. Huk, D. J. Zukor, W. Ralston, A. Lisbona, and A. Petit, "Apoptosis in interface membranes of aseptically loose total hip arthroplasty," Journal of Materials Science: Materials in Medicine, vol. 12, no. 7, pp. 653-658, 2001.

[54] M. L. Wang, R. Tuli, P. A. Manner, P. F. Sharkey, D. J. Hall, and R. S. Tuan, "Direct and indirect induction of apoptosis in human mesenchymal stem cells in response to titanium particles," Journal of Orthopaedic Research, vol. 21, no. 4, pp. 697-707, 2003.

[55] S. Landgraeber, M. Toetsch, C. Wedemeyer et al., "Overexpression of p53/BAK in aseptic loosening after total hip replacement," Biomaterials, vol. 27, no. 15, pp. 3010-3020, 2006.

[56] S. Landgraeber, M. von Knoch, F. Löer et al., "Extrinsic and intrinsic pathways of apoptosis in aseptic loosening after total hip replacement," Biomaterials, vol. 29, no. 24-25, pp. 34443450, 2008.

[57] S. Landgraeber, S. Jaeckel, F. Löer et al., "Pan-caspase inhibition suppresses polyethylene particle-induced osteolysis," Apoptosis, vol. 14, no. 2, pp. 173-181, 2009.

[58] C. Cerri, D. Chimenti, I. Conti, T. Neri, P. Paggiaro, and A. Celi, "Monocyte/macrophage-derived microparticles upregulate inflammatory mediator synthesis by human airway epithelial cells," Journal of Immunology, vol. 177, no. 3, pp. 19751980, 2006.

[59] P. Heyder, I. Bekeredjian-Ding, M. Parcina et al., "Purified apoptotic bodies stimulate plasmacytoid dendritic cells to produce IFN-alpha," Autoimmunity, vol. 40, no. 4, pp. 331-332, 2007.

[60] F. Martinon, V. Pétrilli, A. Mayor, A. Tardivel, and J. Tschopp, "Gout-associated uric acid crystals activate the NALP3 inflammasome," Nature, vol. 440, no. 7081, pp. 237-241, 2006.

[61] R. Medzhitov, "Origin and physiological roles of inflammation," Nature, vol. 454, no. 7203, pp. 428-435, 2008.

[62] J. P.-Y. Ting, S. B. Willingham, and D. T. Bergstralh, "NLRs at the intersection of cell death and immunity," Nature Reviews Immunology, vol. 8, no. 5, pp. 372-379, 2008.

[63] C. Dostert, V. Pétrilli, R. Van Bruggen, C. Steele, B. T. Mossman, and J. Tschopp, "Innate immune activation through Nalp3 inflammasome sensing of asbestos and silica," Science, vol. 320, no. 5876, pp. 674-677, 2008.

[64] V. Hornung, F. Bauernfeind, A. Halle et al., "Silica crystals and aluminum salts activate the NALP3 inflammasome through phagosomal destabilization," Nature Immunology, vol. 9, no. 8, pp. 847-856, 2008.

[65] M. S. Caicedo, R. Desai, K. McAllister, A. Reddy, J. J. Jacobs, and N. J. Hallab, "Soluble and particulate Co-Cr-Mo alloy implant metals activate the inflammasome danger signaling pathway in human macrophages: a novel mechanism for implant debris reactivity," Journal of Orthopaedic Research, vol. 27, no. 7, pp. 847-854, 2009.

[66] V. Pétrilli, C. Dostert, D. A. Muruve, and J. Tschopp, “The inflammasome: a danger sensing complex triggering innate immunity," Current Opinion in Immunology, vol. 19, no. 6, pp. 615-622, 2007.

[67] S. Mariathasan and D. M. Monack, "Inflammasome adaptors and sensors: intracellular regulators of infection and inflammation," Nature Reviews Immunology, vol. 7, no. 1, pp. 31-40, 2007.

[68] L. Burton, D. Paget, N. B. Binder et al., "Orthopedic wear debris mediated inflammatory osteolysis is mediated in part by NALP3 inflammasome activation," Journal of Orthopaedic Research, vol. 31, no. 1, pp. 73-80, 2013.

[69] F. Zhou, J. Lu, X. Zhu et al., "Effects of a cannabinoid receptor 2 selective antagonist on the inflammatory reaction to titanium particles in vivo and in vitro," Journal of International Medical Research, vol. 38, no. 6, pp. 2023-2032, 2010.

[70] J. B. Huang, Y. Ding, D. S. Huang et al., "Inhibition of the PI3K/AKT pathway reduces tumor necrosis factor-alpha production in the cellular response to wear particles in vitro," Artificial Organs, vol. 37, no. 3, pp. 298-307, 2013.

[71] D. Chen, X. Zhang, Y. Guo et al., "MMP-9 inhibition suppresses wear debris-induced inflammatory osteolysis through downregulation of RANK/RANKL in a murine osteolysis model," International Journal of Molecular Medicine, vol. 30, no. 6, pp. 1417-1423, 2012.

[72] Z. Wang, X. Gao, K. Sun, and Q. Jin, "Experimental study on simvastatin in prevention and treatment of aseptic loosening of prosthesis," Zhongguo Xiu Fu Chong Jian Wai Ke Za Zhi, vol. 24, no. 5, pp. 544-547, 2010.

[73] E. M. Schwarz, "WHat potential biologic treatments are available for osteolysis?" The Journal of the American Academy of Orthopaedic Surgeons, vol. 16, pp. S72-S75, 2008.

[74] X. Peng, K. Tao, T. Cheng, J. Zhu, and X. Zhang, "Efficient Inhibition of wear debris-induced inflammation by locally delivered siRNA," Biochemical and Biophysical Research Communications, vol. 377, no. 2, pp. 532-537, 2008.

[75] A. Nehme, G. Maalouf, J.-L. Tricoire, G. Giordano, P. Chiron, and J. Puget, "Effect of alendronate on periprosthetic bone loss after cemented primary total hip arthroplasty: A Prospective Randomized Study," Revue de Chirurgie Orthopedique et Reparatrice de l'Appareil Moteur, vol. 89, no. 7, pp. 593-598, 2003.

[76] T. S. Tapaninen, P. K. Venesmaa, J. S. Jurvelin, H. J. A. Miettinen, and H. P. J. Kröger, "Alendronate reduces periprosthetic bone loss after uncemented primary total hip arthroplasty-a 5-year follow-up of 16 patients," Scandinavian Journal of Surgery, vol. 99, no. 1, pp. 32-37, 2010.

[77] P. K. Venesmaa, H. P. J. Kröger, H. J. A. Miettinen, J. S. Jurvelin, O. T. Suomalainen, and E. M. Alhava, "Alendronate reduces periprosthetic bone loss after uncemented primary total hip arthroplasty: A Prospective Randomized Study," Journal of Bone and Mineral Research, vol. 16, no. 11, pp. 2126-2131, 2001.

[78] K. Yamaguchi, K. Masuhara, S. Yamasaki, T. Nakai, and T. Fuji, "Cyclic therapy with etidronate has a therapeutic effect against local osteoporosis after cementless total hip arthroplasty," Bone, vol. 33, no. 1, pp. 144-149, 2003.

[79] S. Landgraeber, M. Von Knoch, F. Löer et al., "Association between apoptotis and $\mathrm{CD}^{+} / \mathrm{CD}^{+} \mathrm{T}$-lymphocyte ratio in aseptic loosening after total hip replacement," International Journal of Biological Sciences, vol. 5, no. 2, pp. 182-191, 2009. 


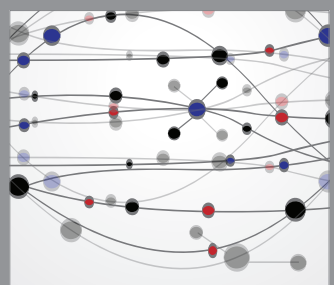

The Scientific World Journal
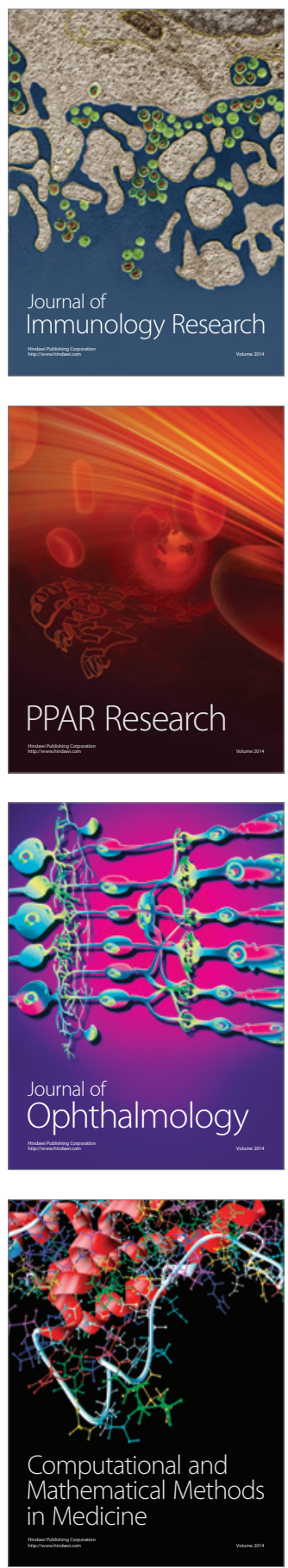

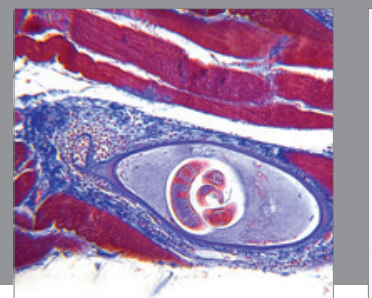

Gastroenterology

Research and Practice
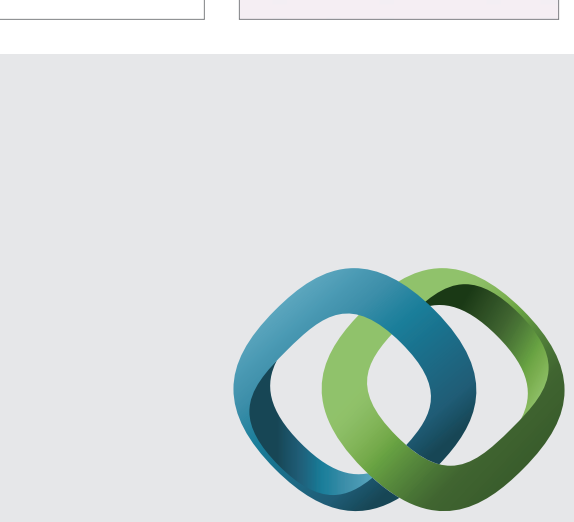

\section{Hindawi}

Submit your manuscripts at

http://www.hindawi.com
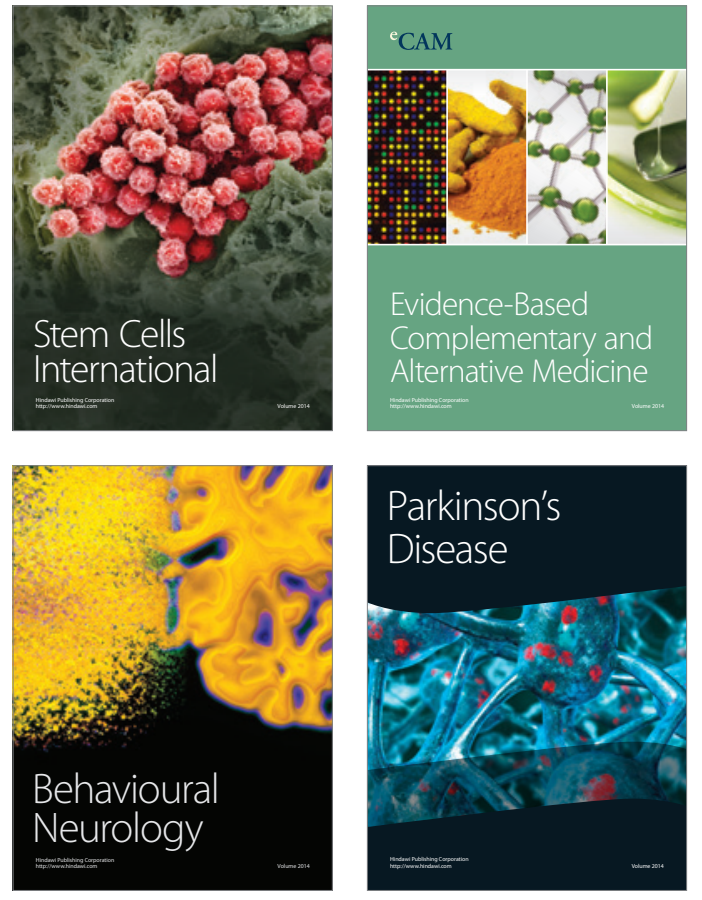
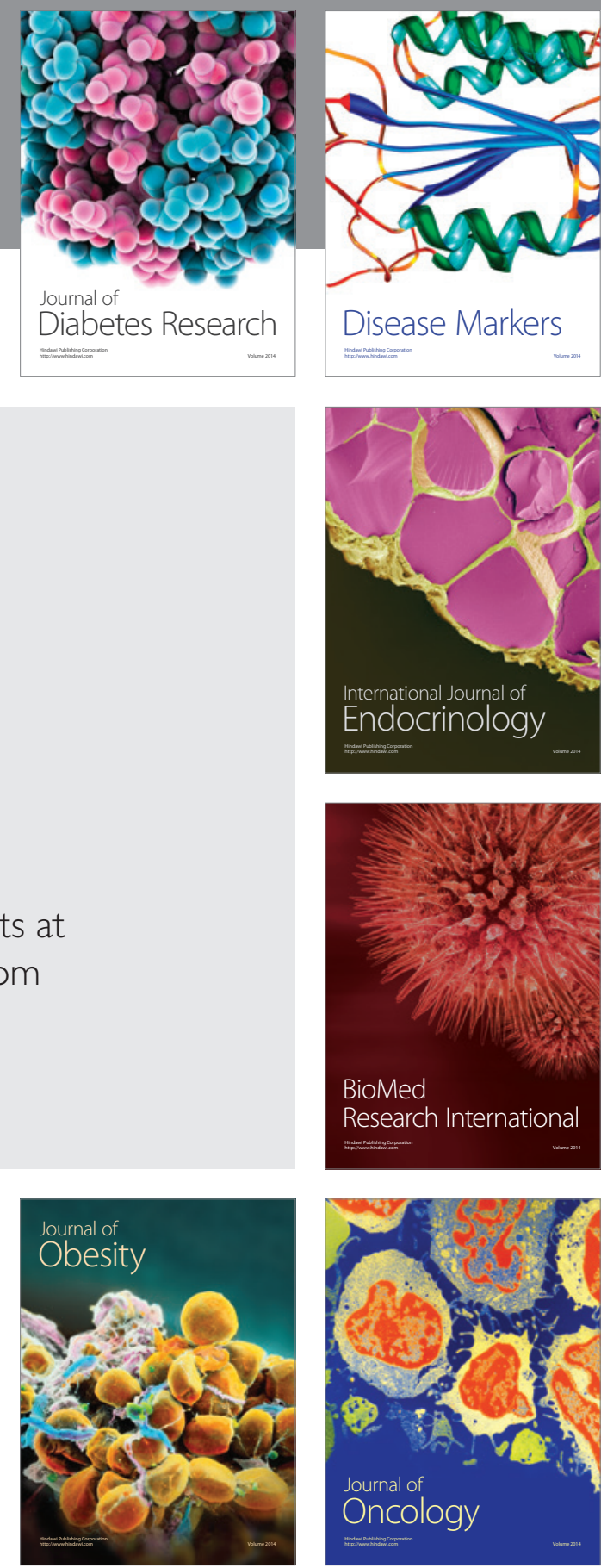

Disease Markers
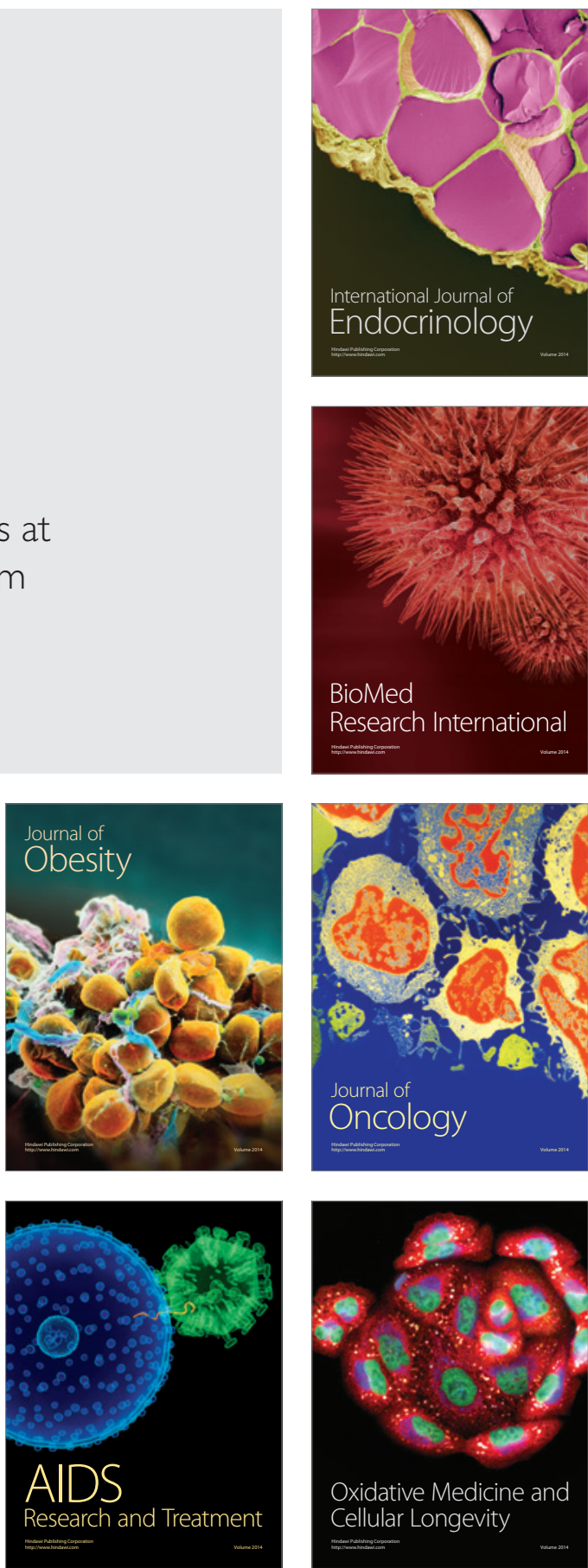